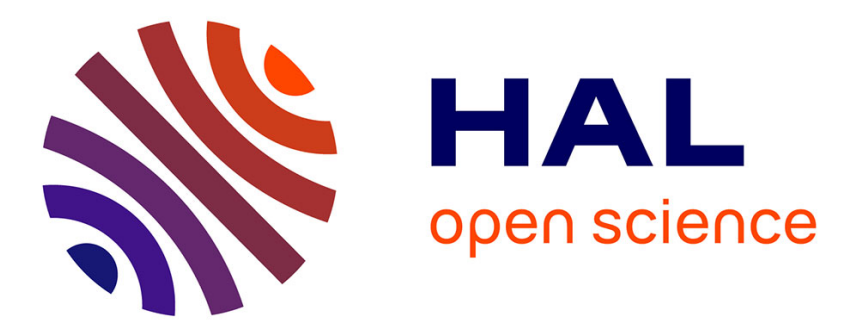

\title{
Automated external defibrillators in the workplace.
} Alexis Descatha, Michel Baer

\section{To cite this version:}

Alexis Descatha, Michel Baer. Automated external defibrillators in the workplace.. BMJ / BMJ (CLINICAL RESEARCH ED); Br Med J; British Medical Journal; Brit Med J, 2008, 337, pp.a1816. inserm-00340609

\section{HAL Id: inserm-00340609 https://www.hal.inserm.fr/inserm-00340609}

Submitted on 21 Nov 2008

HAL is a multi-disciplinary open access archive for the deposit and dissemination of scientific research documents, whether they are published or not. The documents may come from teaching and research institutions in France or abroad, or from public or private research centers.
L'archive ouverte pluridisciplinaire HAL, est destinée au dépôt et à la diffusion de documents scientifiques de niveau recherche, publiés ou non, émanant des établissements d'enseignement et de recherche français ou étrangers, des laboratoires publics ou privés. 


\section{Automated external defibrillators in the workplace}

Alexis Descatha M.D. Ph.D (1,2), Michel Baer M.D. (1).

1. AP-HP, Prehospital Emergency Medical System of Department 92 ("SAMU 92"), Raymond Poincare University hospital, F-92380 Garches, France

2. UVSQ, Occupational health unit/ INSERM U687, Raymond Poincare University hospital, F-92380 Garches, France

\section{Corresponding author:}

Dr. Alexis Descatha - Unité de pathologie professionnelle/ SAMU 92. CHU Raymond Poincaré 104 Bd Poincaré, 92380 Garches, France

alexis.descatha@rpc.aphp.fr

Phone: +33147107754 Fax: +33147107768

Key words: cardiac arrest, defibrillation, workplace, health plan implementation

Total word count: 990

1/ All authors declare that the answers to the questions on your competing interest form [http://bmj.com/cgi/content/full/317/7154/291/DC1] are all No and therefore have nothing to declare

2/ The Corresponding Author has the right to grant on behalf of all authors and does grant on behalf of all authors, an exclusive licence (or non exclusive for government employees) on a worldwide basis to the BMJ Publishing Group Ltd, and its Licensees to permit this article (if accepted) to be published in BMJ editions and any other BMJPGL products and to exploit all subsidiary rights, as set out in our licence at http://resources.bmj.com/bmj/authors/checklists-forms/licence-for-publication)." 
The evidence that automated external defibrillators (AED) are effective in terms of survival in the management of out-of-hospital cardiac arrest (OHCA). As the survival rate decreases exponentially with the interval between OHCA and defibrillation, the locations of first responder and AED are particularly important. However, there is a persistent controversy concerning the recommended sites of AED and the personnel who need to be trained ${ }^{1}$.

AED in the workplace is a controversial issue at the present time, as the incidence of OHCA in the workplace is usually low, which probably partly explains the very small number of studies on AED in the workplace. A review of literature on defibrillation in the workplace revealed only one specific original (retrospective) study on this subject, while six other studies described AED in various setting, including the workplace ${ }^{1-6}$. OHCA in the workplace represented between 1 and $6 \%$ of all OHCA reported in these studies, varying according to the definition of "workplace", as one of the difficulties of studies of the management of OHCA in the workplace is the heterogeneous definition of the workplace, ranging from small shops to large factories. Nevertheless, most studies agree that the workplace is one of the least frequent sites of $\mathrm{OHCA}^{1 ; 3-6}$, regardless of the type of workplace (with the exception of large industrial sites).

Several authors have also reported that patients experiencing OHCA in the workplace presented one of the highest hospital discharge survival rates ${ }^{2 ; 5 ; 6}$. OHCA also tends to occur in young people ${ }^{6}$, which implies that the number of years of life saved is generally high. We can therefore conclude that, although OHCA is a relatively rare event, AED in the workplace appears to be potentially effective, which is why some countries have established guidelines for the use of AED in the workplace ${ }^{7 ; 8}$. 
In view of the heterogeneity of workplaces and in order to increase cost-effectiveness due to the low incidence of OHCA in the workplace, high-risk occupational settings should be identified, taking into account criteria of feasibility and efficacy of AED. Based on expert opinions and studies conducted in other settings, the existing guidelines on installation of AED in the workplace are based on the site-specific incidence of OHCA (with a lower limit of one OHCA every two or five years, depending on the study), or based on the number of employees on site and their mean age. However, other parameters also need to be taken into account, such as the number and characteristics of visitors (with the same lower limit or more than 250 people over the age of 50 present for more than 16 hours per day ${ }^{9}$ ), the presence of occupational risk factors for ventricular fibrillation (high voltage, high cardiac risk situations...), and the medical profile of employees/visitors (high prevalence of risk factors for coronary heart disease or sudden death).

However, the question of who is at high risk of sudden death is currently debated ${ }^{10}$. Bardy et al., in the Home AED Trial, partly explained the failure of their treatment by the recent improvement in the management of cardiovascular disease (including implantable defibrillator) and an increase of other causes of mortality ${ }^{11}$.

Other environmental factors should also be taken in account, such as the time to arrival of specialized emergency units, the social environment and the resuscitation skills of the population considered. Although installation of AED in workplaces in which management and employees are convinced of the value of AED and first-aid training would be clearly beneficial, the benefit is much less obvious in a context of limited interest and poor understanding of AED.

After deciding to equip the workplace with AED, it is essential to develop a complete AED programme supported by management: this programme must comprise the exact location of 
the AED, but also a protocol describing each link of the survival chain from loss of consciousness to the arrival of specialized emergency services, regular training of first responders as well as a quality assurance programme (including maintenance and revision of AED protocols). In 2002, the American College of Occupational and Environmental Medicine (ACOEM) developed a complete 12-point programme ${ }^{7}$. To shorten the interval between OHCA and defibrillation, the workplace AED programme must define the alarm procedure and the first minutes of care. Depending on the workplace emergency plan of the company (which must comprise the AED protocol), AED must be accessible to all and must be able to be brought to the victim within the first five minutes after onset of the malaise ${ }^{7}$, or must be given to an emergency team trained in cardiopulmonary resuscitation/AED. Studies in other settings have shown that first responders equipped with AED may be more effective than public access AED only ${ }^{12}$. Similarly, some emphasized the importance of regular training in the use of AED ${ }^{11}$, which is simpler for experienced teams than for all personnel. Nevertheless, all personnel must be familiar with basic life support and the workplace medical emergency plan. The importance of regular training (including drills) and assessment of this training in the context of a quality assurance programme must also be stressed to allow regular improvement of AED programme.

In conclusion, the workplace, which can be defined as a heterogeneous place attended by young people generally in good health and working together, is a useful site for AED, despite the absence of cost-effectiveness studies and the low incidence of OHCA in the workplace. The cost-effectiveness balance must be assessed for each workplace based on discussion between employers, employees, emergency physicians, occupational physicians, and health and safety experts, and a global AED programme must be implemented in order to be effective in the event of OHCA. Furthermore, in view of the rarity of OHCA compared to 4 
other occupational health issues that may be more important for some companies and the possible role of the State in a public health programme designed to reduce sudden death, the question of the funding of AED remains unresolved.

\section{References}

1. Engdahl J..Herlitz J. Localization of out-of-hospital cardiac arrest in Goteborg 1994-2002 and implications for public access defibrillation. Resuscitation 2005;64:171-5.

2. Descatha A, Frederic M, Devere C, Dolveck F, Goddet S, Baer M et al. Details of the initial management of cardiac arrest occurring in the workplace in a French urban area. Resuscitation 2005;65:301-7.

3. Becker L, Eisenberg M, Fahrenbruch C, Cobb L. Public locations of cardiac arrest. Implications for public access defibrillation. Circulation 1998;97:2106-9.

4. Reed DB, Birnbaum A, Brown LH, O'Connor RE, Fleg JL, Peberdy MA et al. Location of cardiac arrests in the public access defibrillation trial. Prehosp.Emerg.Care 2006;10:61-76.

5. Muraoka H, Ohishi Y, Hazui H, Negoro N, Murai M, Kawakami M et al. Location of out-of-hospital cardiac arrests in Takatsuki City: where should automated external defibrillator be placed. Circ.J. 2006;70:827-31.

6. Rudner R, Jalowiecki P, Wartak M, Marciniak R, Byrczek T. The effects of selected factors on survival of out-of-hospital cardiac arrest victims. Anest.Intens.Ter. 2005;37:174-80.

7. Starr LM. Automated external defibrillation in the occupational setting. J Occup.Environ.Med 2002;44:2-7.

8. de Nichilo G, Carucci MS, Bisceglia L, Gallo A, Di Candia O, Assennato G. [Semiautomatic defibrillators at the workplace health service]. G.Ital.Med.Lav.Ergon. 2003;25 Suppl:282-3.

9. Ornato JP, McBurnie MA, Nichol G, Salive M, Weisfeldt M, Riegel B et al. The Public Access Defibrillation (PAD) trial: study design and rationale. Resuscitation 2003;56:135-47.

10. McKee M,.McKee D. Public access defibrillation: how to maximise the gain. Heart 2008;94:260-1.

11. Bardy GH, Lee KL, Mark DB, Poole JE, Toff WD, Tonkin AM et al. Home use of automated external defibrillators for sudden cardiac arrest. N.Engl.J.Med. 2008;358:1793-804

12. Pell JP, Sirel JM, Marsden AK, Ford I, Walker NL, Cobbe SM. Potential impact of public access defibrillators on survival after out of hospital cardiopulmonary arrest: retrospective cohort study. BMJ 2002;325:515-19. 